\title{
Azilsartan improves the effects of etanercept in patients with active rheumatoid arthritis: a pilot study
}

This article was published in the following Dove Press journal: Therapeutics and Clinical Risk Management

\author{
Naza Mohammed Ali \\ Mahmood' \\ Saad Abdulrahman Hussain ${ }^{2}$ \\ Raouf Rahim Mirza ${ }^{3}$ \\ 'Department of Pharmacology and \\ Toxicology, College of Pharmacy, \\ University of Sulaimani, Kurdistan \\ Region, Iraq; ${ }^{2}$ Department of \\ Pharmacology and Toxicology, Faculty \\ of Pharmacy, Al-Rafidain University \\ College, Baghdad, Iraq; ${ }^{3}$ Department \\ of Medicine, College of Medicine, \\ University of Sulaimani, Kurdistan \\ Region, Iraq
}

Background and aim: Much evidence has emerged documenting the involvement of the renin-angiotensin system (RAS) in inflammatory processes. The objective of this study was to evaluate the effects of blocking RAS with azilsartan (Azil) on the clinical efficacy of etanercept (Etan) in patients with active rheumatoid arthritis (RA).

Patients and methods: Forty-two patients diagnosed with active RA and poorly responding to methotrexate were enrolled in this pilot clinical study. They were randomly allocated into two groups, and treated with either Etan $(50 \mathrm{mg} /$ week $)$ and placebo or the same dose of Etan with Azil (20 mg/day) for 90 days. The clinical outcome was evaluated using the Disease Activity Score-28 joint (DAS-28), simplified disease activity index (SDAI), clinical disease activity index (CDAI) and the health assessment questionnaire disease index (HAQ-DI). Blood samples were obtained for the assessment of C-reactive protein and erythrocyte sedimentation rate at baseline and after 90 days.

Results: The markers of pain and disease activity, C-reactive protein and erythrocyte sedimentation rate were significantly improved when Azil was used, as an adjuvant with Etan, compared with the use of Etan and placebo.

Conclusion: Blocking RAS with azilsartan may improve the effects of etanercept on the clinical markers of pain and disease severity of patients with active RA not responding to methotrexate.

Keywords: etanercept, azilsartan, rheumatoid arthritis, DAS-28, HAQ-DI, SDAI

\section{Introduction}

Inflammatory processes are complicated responses of various tissues toward many kinds of noxious stimuli, including foreign bodies, pathogens and traumatic injuries. ${ }^{1}$ Although these responses are beneficial, they may be associated with inflammatory diseases like rheumatoid arthritis (RA) and many other immune-mediated disorders when excessively initiated. ${ }^{2}$ Currently, many pharmacological agents are clinically utilized for RA treatment, including disease-modifying drugs such as methotrexate and biological agents such as etanercept (Etan). ${ }^{3}$ However, the adverse effects profile and cost burden limit their wide and successful use, particularly in poorly funded health care systems. ${ }^{4}$ During RA pathogenesis, the excessive oxidative burden associated with the inflammatory response can amplify and worsen tissue damage associated with these responses. ${ }^{5}$ Therefore, modulation of the oxidative damage, through targeting other pathways, may add further clinical benefits to the currently used anti-rheumatic agents. ${ }^{6}$ The reninangiotensin system (RAS) is classically recognized as a regulator of the cardiovascular function with a primary role in controlling blood pressure. ${ }^{7}$ However, much evidence
Correspondence: Saad Abdulrahman Hussain

Department of Pharmacology and Toxicology, Faculty of Pharmacy, Al-Rafidain University College, 10052 Al-Mustansiriya St. 75, Baghdad, Iraq Tel +96479 0l7I 2624

Email saad.hussain@coalrafidain.edu.iq
Therapeutics and Clinical Risk Management 2018:14 I379-I385

1379

Dovepress in 0

http://dx,doi.org/10.2147/TCRM.S174693 (c) (1) (5) 2018 Mahmood et al. This work is published and licensed by Dove Medical Press Limited. The full terms of this license are available at https://www.dovepress.com/terms.php cc. ${ }_{\mathrm{BY}} \mathrm{NC}$ and incorporate the Creative Commons Attribution - Non Commercial (unported, v3.0) License (http://creativecommons.org/licenses/by-nc/3.0/). By accessing the work you hereby accept the Terms. Non-commercial uses of the work are permitted without any further permission from Dove Medical Press Limited, provided the work is properly attributed. For permission for commercial use of this work, please see paragraphs 4.2 and 5 of our Terms (https://www.dovepress.com/terms.php). 
has emerged documenting the involvement of RAS in the inflammatory processes. ${ }^{8}$ Moreover, angiotensin II (Ang II) is shown to activate pro-inflammatory mediators including $\mathrm{NF}-\kappa \mathrm{B}$, with consequent exaggeration of inflammationmediated tissue damage. ${ }^{9}$ Additionally, Ang II was involved in the upregulation of pro-inflammatory cytokines such as IL-1, IL-6 and TNF- $\alpha,{ }^{10}$ and accordingly, it may contribute to the pathogenesis of RA. It has been previously reported that in rats with adjuvant-induced arthritis, treatment with losartan attenuates cartilage tissue damage and improves the signs and symptoms of inflammation. ${ }^{11,12}$ In the present study, we aim to evaluate the clinical significance of the adjuvant use of azilsartan (Azil), an AT1 blocker, in patients with active RA maintained on etanercept.

\section{Patients and methods}

\section{Patient recruitment and study design}

A double-blind, placebo-controlled randomized pilot clinical study was performed with a 12-week treatment period over 14 months (from June 2016 to August 2017) at the Specialized Center of Rheumatology, Sulaimani, Iraq. Of the 47 patients screened for eligibility, 44 patients with active moderate to severe RA were enrolled (age range 18-69 years), based on 2010 ACR/EULAR criteria ${ }^{13}$ and
Disease Activity Score-28 joint (DAS-28) $\geq 3$.2. All patients showed inadequate response to oral methotrexate (MTX) (doses ranged between $7.5 \mathrm{mg} /$ week and $25 \mathrm{mg} /$ week for at least 3 months) at the time of screening eligibility for inclusion and were a candidate for initiation of treatment with Etan. The patients were switched to receiving Etan alone, and they initially treated with Etan concomitantly with the already administered dose of MTX, which was reduced and discontinued over a 2-week period. Then treatment with Etan was continued as monotherapy for the rest of the assigned treatment period (90 days). ${ }^{14}$ The eligible patients were randomly allocated to either of two treatment groups in a $1: 1$ ratio: etanercept and placebo-treated $($ Etan + placebo, $n=22)$ or to etanercept + azilsartan $($ Etan + Azil, n=22). Etanercept was administered by subcutaneous injection ( $50 \mathrm{mg}$ per injection) once weekly, while the placebo formula and azilsartan (20 mg/day) were administered as single oral daily doses. The azilsartan (Apollo Healthcare Resources, Singapore) doses were prepared as capsule dosage form and administered as an adjuvant with the regularly used etanercept regimen (Amgen Inc., Thousand Oaks, CA, USA). Only 36 patients completed the study (Figure 1). The patients were instructed to continue their regular drug treatment schedule and were clinically observed every four weeks for any unusual adverse effects.

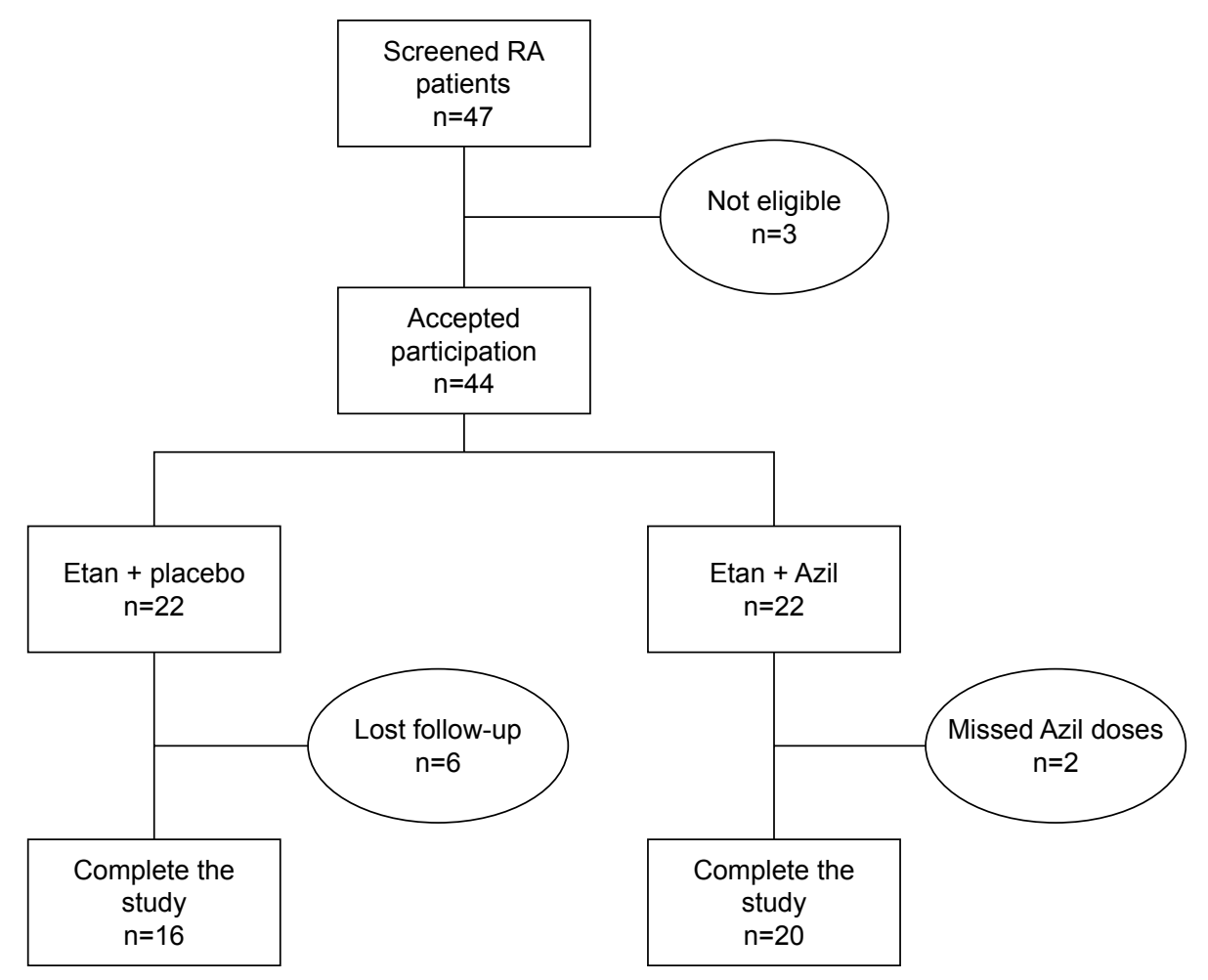

Figure I Flow chart of the study.

Abbreviations: Azil, azilsartan; Etan, etanercept; RA, rheumatoid arthritis. 
All participants provided signed informed consent form according to the principles of the Declaration of Helsinki. The local scientific ethics committee of the University of Sulaimani, College of Medicine approved the study protocol (no. SA 507/1024).

\section{Outcome measurement and follow up}

At the time of inclusion, patients with one of the following characteristics were excluded: patients using nonsteroidal anti-inflammatory drugs 2 days before inclusion, hypersensitivity or severe adverse effects to the tested drugs, renal or hepatic damage, pregnant and breastfeeding women, juvenile RA, patients using disease-modifying anti-rheumatic drugs (DMARDs) other than etanercept or high dose steroids (prednisolone $>10 \mathrm{mg} /$ day, or its equivalent), patients using ARBs or ACEIs for treatment of hypertension, missing medication for two consecutive days, coexistence of other connective tissue disorders, and mild or inactive RA. To evaluate the clinical efficacy endpoints at baseline and at the end of 12-week treatment period, four instruments for clinical outcome assessment of the treatment were utilized, including the DAS-28, ${ }^{15}$ simplified disease activity index (SDAI), ${ }^{16}$ clinical disease activity index (CDAI), ${ }^{17}$ and the health assessment questionnaire disease index (HAQ-DI) that assesses functional ability for eight subscales: arising, common daily activities, dressing, eating, grip, hygiene, reach and walking. Blood samples were obtained from each patient by vein puncture at baseline and the end of the study. Of the collected blood, $3 \mathrm{~mL}$ was kept in an ethylene diamine tetra-acetic acid tube to be used for measurement of erythrocyte sedimentation rate (ESR). The remaining blood was kept in a plain tube and left to coagulate at room temperature for at least 30 minutes, and centrifuged for 10 minutes at 4,000 rpm to obtain serum. Using ready-made enzyme-linked immunosorbent assay kits, the resultant serum was utilized for the measurement of C-reactive protein (CRP) (Demeditec, Kiel, Germany).

\section{Statistical analysis}

All data were statistically analyzed using Graph Pad Prism 5.1 software (Graph Pad Software Inc., La Jolla, CA, USA). Continuous variables were presented as a mean \pm SD and discrete variables presented as numbers and frequencies. The Chi-square and Wilcoxon-rank tests were used for independence to test the significance of the association between discrete variables. The paired $t$-test was used to evaluate the difference between pre- and post-treatment values, while unpaired $t$-test was used to compare means of the two groups post-treatment. Moreover, one-way analysis of variance
(ANOVA) was utilized to evaluate the significance of the difference between means of independent samples, and supported by Bonferroni's post hoc analysis. Values with $P<0.05$ were considered significantly different.

\section{Results}

At baseline, the data presented in Table 1 showed no significant differences between the two groups involved in the study regarding their demographic characteristics. In Table 2, although the DAS-28 score was not significantly different at baseline, the result showed that both treatments significantly decreased the DAS-28 score; however, the combination of etanercept and azilsartan produced a significantly greater decrease in this score compared with etanercept and placebo. Meanwhile, the SDAI score was not significantly changed in the etanercept and placebo-treated group and the combination produced a significant decrease in this parameter compared with baseline and etanercept and placebo arm values after 90 days. Regarding the effects on the HAQ-DI score, the data indicated that the baseline values were not

Table I Demographic data and baseline characteristics of the RA patients treated with Etan or its combination with Azil

\begin{tabular}{|c|c|c|c|}
\hline Parameters & $\begin{array}{l}\text { Etan + placebo } \\
N=16\end{array}$ & $\begin{array}{l}\text { Etan + Azil } \\
\mathbf{N}=\mathbf{2 0}\end{array}$ & $P$-value \\
\hline \multicolumn{4}{|l|}{ Gender, n (\%) } \\
\hline Male & $4(25)$ & $6(30)$ & 0.4 \\
\hline Female & $12(75)$ & $14(70)$ & 0.32 \\
\hline Age (years) & $47.9 \pm 11.7$ & $45.7 \pm 10.4$ & 0.56 \\
\hline Body weight (kg) & $88.5 \pm 17.5$ & $86.8 \pm 15.6$ & 0.18 \\
\hline BMI $\left(\mathrm{kg} / \mathrm{m}^{2}\right)$ & $32.1 \pm 2.7$ & $33.1 \pm 3.0$ & 0.38 \\
\hline Disease duration (year) & $7.2 \pm 2.6$ & $8.5 \pm 2.4$ & 0.12 \\
\hline MTX treatment (months) & $35.3 \pm 7.0$ & $34.6 \pm 5.8$ & 0.76 \\
\hline ESR $(\mathrm{mm} / \mathrm{h})$ & $49.8 \pm 14.3$ & $48.5 \pm 15.8$ & 0.49 \\
\hline $\mathrm{CRP}(\mu g / \mathrm{mL})$ & $9.8 \pm 5.5$ & $12.0 \pm 4.5$ & 0.38 \\
\hline DAS-28 score (four values) & $6.0 \pm 0.57$ & $6.4 \pm 0.82$ & 0.12 \\
\hline SDAI score & $26.4 \pm 3.9$ & $27.2 \pm 4.9$ & 0.59 \\
\hline HAQ-DI score & $1.9 \pm 0.30$ & $2.04 \pm 0.37$ & 0.28 \\
\hline CDAl score & $30.4 \pm 6.4$ & $30.2 \pm 4.9$ & 0.94 \\
\hline Joint deformities, $n$ (\%) & $5(3 \mid .4)$ & $7(35.0)$ & 0.40 \\
\hline $\begin{array}{l}\text { Use of steroids ( }<10 \mathrm{mg} / \text { day } \\
\text { prednisolone), } \mathrm{n}(\%)\end{array}$ & $4(25)$ & $5(22.7)$ & 0.62 \\
\hline Use of NSAIDs, n (\%) & $7(43.8)$ & $10(45.5)$ & 0.58 \\
\hline \multicolumn{4}{|l|}{ Associated diseases, n (\%) } \\
\hline Hypertension, n (\%) & $15(93.8)$ & $17(85.0)$ & 0.19 \\
\hline Diabetes mellitus, n (\%) & $2(12.5)$ & $3(15.0)$ & 0.32 \\
\hline Smoking habits, n (\%) & I (6.2) & $2(10.0)$ & 0.14 \\
\hline
\end{tabular}

Note: Data shown as mean \pm SD unless indicated otherwise.

Abbreviations: Azil, azilsartan; CDAl, clinical disease activity index; CRP, C-reactive protein; DAS-28, 28-joint Disease Activity Score; ESR, erythrocyte sedimentation rate; Etan, etanercept; HAQ-DI, health assessment questionnaire disease index; MTX, methotrexate; RA, rheumatoid arthritis; SDAl, simplified disease activity index. 
Table 2 Effect of Azil on DAS-28, SDAI, HAQ-DI, and CDAI of patients with active RA maintained on Etan

\begin{tabular}{llllll}
\hline Clinical & \multicolumn{2}{l}{ Etan + placebo $\mathbf{( N = 1 6 )}$} & & \multicolumn{2}{l}{ Etan + Azil $\mathbf{( N = 2 0 )}$} \\
\cline { 2 - 3 } score & $\begin{array}{l}\text { Zero } \\
\text { time }\end{array}$ & $\begin{array}{l}\text { After } \\
\mathbf{9 0} \text { days }\end{array}$ & & $\begin{array}{l}\text { Zero } \\
\text { time }\end{array}$ & $\begin{array}{l}\text { After } \\
\mathbf{9 0} \text { days }\end{array}$ \\
\hline DAS-28 & $6.01 \pm 0.57^{\mathrm{a}}$ & $4.9 \pm 0.5^{\mathrm{b}, *}$ & & $6.4 \pm 0.82^{\mathrm{a}}$ & $4.4 \pm 0.23^{\mathrm{c}, *}$ \\
SDAI & $26.4 \pm 3.9^{\mathrm{a}}$ & $23.4 \pm 3.7^{\mathrm{a}}$ & & $27.2 \pm 4.9^{\mathrm{a}}$ & $18.1 \pm 4.2^{\mathrm{b}, *}$ \\
HAQ-DI-DI & $1.9 \pm 0.3^{\mathrm{a}}$ & $1.6 \pm 0.2^{\mathrm{b}, *}$ & & $2.0 \pm 0.4^{\mathrm{a}}$ & $1.3 \pm 0.3^{\mathrm{c}, *}$ \\
CDAI & $30.4 \pm 6.4^{\mathrm{a}}$ & $23.1 \pm 5.7^{\mathrm{b}, *}$ & & $30.2 \pm 4.9^{\mathrm{a}}$ & $19.3 \pm 4.8^{\mathrm{c}, *}$ \\
\hline
\end{tabular}

Notes: Data shown as mean \pm SD. *Significantly different from baseline in each group (paired $t$-test, $P<0.05)$. Values with non-identical superscripts $(a, b, c)$ among groups were significantly different (ANOVA, $P<0.05$ ).

Abbreviations: ANOVA, analysis of variance; Azil, azilsartan; CDAl, clinical disease activity index; CRP, C-reactive protein; DAS-28, 28-joint Disease Activity Score; ESR, erythrocyte sedimentation rate; Etan, etanercept; HAQ-DI, health assessment questionnaire disease index; MTX, methotrexate; RA, rheumatoid arthritis; SDAI, simplified disease activity index.

significantly different, and both treatments approach significantly decreased HAQ-DI score after 90 days of treatment; however, the addition of azilsartan produced a significantly greater decrease in this score compared with the use of placebo with etanercept. Moreover, Table 2 showed that both treatment approaches significantly decreased the CDAI score after 90 days of treatment, and the combination of etanercept with azilsartan produced a significantly greater decrease in the CDAI value compared with addition of placebo with etanercept. Table 3 indicated that both treatments approaches significantly improved TJC and SJC, with the prominent effect of the combination with azilsartan, where the decrease in TJC and SJC was significantly greater than that produced by etanercept and placebo. Regarding the effects on the VAS-100 score, both treatments approach significantly improved VAS-100 score, and their effects were comparable $(P>0.05)$ after 90 days. Table 3 also showed that both treatments approaches significantly decreased the EGA score

Table 3 Effect of Azil on different functional areas of the DAS-28 score of patients with active RA maintained on Etan

\begin{tabular}{|c|c|c|c|c|}
\hline \multirow[t]{2}{*}{ Clinical score } & \multicolumn{2}{|c|}{$\begin{array}{l}\text { Etan + placebo } \\
(\mathbf{N}=16)\end{array}$} & \multicolumn{2}{|c|}{$\begin{array}{l}\text { Etan }+ \text { Azil } \\
(\mathbf{N}=\mathbf{2 0})\end{array}$} \\
\hline & $\begin{array}{l}\text { Zero } \\
\text { time }\end{array}$ & $\begin{array}{l}\text { After } \\
90 \text { days }\end{array}$ & $\begin{array}{l}\text { Zero } \\
\text { time }\end{array}$ & $\begin{array}{l}\text { After } \\
90 \text { days }\end{array}$ \\
\hline TJC & $12.6 \pm 3.1^{a}$ & $8.9 \pm 4.2^{\mathrm{b}, *}$ & $11.3 \pm 3.6^{\mathrm{a}}$ & $6.9 \pm 2.9 c, *$ \\
\hline SJC & $5.3 \pm 1 . I^{a}$ & $3.9 \pm I . I^{b, *}$ & $4.6 \pm 1.5^{a}$ & $1.9 \pm 1.5^{c, *}$ \\
\hline VAS-I00 (mm) & $65 \pm 9.8^{\mathrm{a}}$ & $55.6 \pm 10.9^{b, *}$ & $68 \pm 12.8^{a}$ & $51.3 \pm 6.5^{\mathrm{b}, *}$ \\
\hline $\mathrm{EGA}(\mathrm{cm})$ & $6.6 \pm 0.8 \mathrm{I}^{\mathrm{a}}$ & $5.3 \pm 0.87^{b, *}$ & $6.7 \pm 0.92^{\mathrm{a}}$ & $4.2 \pm 0.8 I^{c, *}$ \\
\hline Morning stiffness (min) & $32.5 \pm 20.4^{\mathrm{a}}$ & $25.1 \pm 17.8^{\mathrm{a}}$ & $29.0 \pm 18.4^{\mathrm{a}}$ & $13.3 \pm 1 \mid .7^{\mathrm{b}, *}$ \\
\hline
\end{tabular}

Notes: Data shown as mean \pm SD. *Significantly different from baseline in each group (paired $t$-test, $P<0.05)$. Values with non-identical superscripts $(a, b, c)$ among groups were significantly different (ANOVA, $P<0.05$ ).

Abbreviations: ANOVA, analysis of variance; Azil, azilsartan; DAS-28, 28-joint Disease Activity Score; EGA, evaluator global assessment; Etan, etanercept; RA, rheumatoid arthritis; SJC, swollen joint count; TJC, tender joint count; VAS, visual analog score. compared to the baseline values, and the combination with azilsartan produced superior effect compared with the use of placebo with etanercept $(P<0.05)$. Moreover, the Etan-Azil combination significantly improved the duration of morning stiffness $(P<0.05)$ compared with both the baseline value and the effect of combining placebo and etanercept, which did not show a significant effect in this regard (Table 3). The influence of using placebo with etanercept or the combination of the later with azilsartan on the different functional areas of HAQ-DI was shown in Table 4. The use of etanercept and placebo improves all functional areas except that of "Reach" and "Grip", compared with baseline values; while its combination with azilsartan improves all the HAQ-DI functional areas after 90 days of treatment, compared with baseline values $(P<0.05)$. When both treatment approaches were compared, Etan + Azil was found to be superior over Etan + placebo regarding the effects on "Eat" and "Walk" areas $(P<0.05)$. Figure 2 showed that Etan-Azil combination produced a significant decrease in ESR compared with baseline value, and also significantly different compared to the effect of Etan + placebo after 90 days. Meanwhile, both treatment approaches produced a significant decrease in serum CRP levels $(P<0.05)$ compared with baseline values, and the addition of azilsartan produced superior effect compared with the use of placebo and etanercept (Figure 3).

\section{Discussion}

Apart from its well-defined role as a cardiovascular function regulator, RAS is well recognized as a modulator of many physiological functions, including the inflammatory response and immune cell function. ${ }^{18,19}$ It has been reported that local RAS was highly expressed in various tissues and organs including the immune system cells and synovial tissues, which may generate Ang II concentrations many times more than that found in plasma. ${ }^{20}$ Therefore, the locally elevated Ang II levels may enhance inflammatory disorders that may definitely predispose to arthritis-related degenerations. ${ }^{21}$ Based on much evidence suggesting the anti-inflammatory activities of agents that block the RAS activity, including ACEIs and ARBs, ${ }^{22-24}$ we evaluated the adjuvant use of azilsartan, one of the newly approved ARBs, with etanercept and the effect on the clinical markers of patients with RA patients poorly responding to methotrexate. In the present study, we demonstrated for the first time that co-administration of azilsartan with etanercept in the treatment of active RA may augment the efficacy of the later to improve the clinical marker score of the disease. In addition to improving ESR and serum CRP of the included RA 
Table 4 Effect of Azil on different functional areas of HAQ-DI score of patients with active RA maintained on Etan

\begin{tabular}{|c|c|c|c|c|c|c|}
\hline \multirow[t]{2}{*}{ Parameters } & \multicolumn{3}{|c|}{ Etan + placebo $(\mathrm{N}=16)$} & \multicolumn{3}{|c|}{ Etan + Azil $(\mathbf{N}=\mathbf{2 0})$} \\
\hline & $\begin{array}{l}\text { Zero } \\
\text { time }\end{array}$ & $\begin{array}{l}\text { After } \\
\mathbf{9 0} \text { days }\end{array}$ & $\%$ change & $\begin{array}{l}\text { Zero } \\
\text { time }\end{array}$ & $\begin{array}{l}\text { After } \\
90 \text { days }\end{array}$ & \% change \\
\hline Dress & $1.6 \pm 0.8^{a}$ & $0.8 \pm 0.7^{\mathrm{b}, *}$ & $50.3 \downarrow$ & $1.6 \pm 0.6^{a}$ & $0.7 \pm 0.6^{\mathrm{b}, *}$ & $58.1 \downarrow$ \\
\hline Arise & $1.5 \pm 0.7^{\mathrm{a}}$ & $\mathrm{I} . \mathrm{I} \pm 0.5^{\mathrm{b}, *}$ & $41.5 \downarrow$ & $1.7 \pm 0.8^{\mathrm{a}}$ & $0.8 \pm 0.6^{\mathrm{b}, *}$ & $55.8 \downarrow$ \\
\hline Eat & $1.8 \pm 0.8^{\mathrm{a}}$ & $1.3 \pm 0.8^{\mathrm{b}, *}$ & $30.9 \downarrow$ & $2.1 \pm 0.7^{a}$ & $0.7 \pm 0.5^{c, *}$ & $66.6 \downarrow$ \\
\hline Walk & $1.9 \pm 0.8^{a}$ & $1.4 \pm 0.7^{\mathrm{b}, *}$ & $19.1 \downarrow$ & $2.2 \pm 0.9^{a}$ & $0.9 \pm 0.6^{c, *}$ & $59.1 \downarrow$ \\
\hline Hygiene & $1.6 \pm 0.9^{a}$ & I. $I \pm 0.9^{\mathrm{b}, *}$ & $34.9 \downarrow$ & $1.9 \pm 0.7^{\mathrm{a}}$ & $0.7 \pm 0.7^{\mathrm{b}, *}$ & $65.8 \downarrow$ \\
\hline Reach & $2.1 \pm 0.9^{a}$ & $1.9 \pm I . I^{\mathrm{a}}$ & $11.9 \downarrow$ & $2.6 \pm 0.7^{\mathrm{a}}$ & $1.2 \pm 0.6^{\mathrm{b}, *}$ & $53.8 \downarrow$ \\
\hline Grip & $1.6 \pm 0.6^{\mathrm{a}}$ & $1.2 \pm 0.8^{\mathrm{a}}$ & $24.4 \downarrow$ & $1.8 \pm 0.7^{a}$ & $0.7 \pm 0.6^{\mathrm{b}, *}$ & $60.0 \downarrow$ \\
\hline Daily activity & $2.0 \pm 0.9^{\mathrm{a}}$ & $1.5 \pm 1.0^{\mathrm{b}, *}$ & $25.0 \downarrow$ & $2.6 \pm 0.8^{a}$ & $1.2 \pm 0.7^{\mathrm{b}, *}$ & $47.1 \downarrow$ \\
\hline
\end{tabular}

Notes: Data shown as mean \pm SD. *Significantly different from baseline in each group (paired $t$-test, $P<0.05$ ). Values with non-identical superscripts (a, b, c) among groups were significantly different (ANOVA, $P<0.05$ ).

Abbreviations: ANOVA, analysis of variance; Azil, azilsartan; Etan, etanercept; HAQ-DI, health assessment questionnaire disability index; RA, rheumatoid arthritis.

patients, the reported improvement in the clinical score of the clinical evaluation systems produced by the addition of azilsartan to the treatment protocol was in tune with the previously reported anti-inflammatory activities of many other ARBs in vitro and in vivo. ${ }^{25,26}$ Moreover, the antiinflammatory activity of azilsartan is recognized in various animal models of tissue damage and inflammation associated with metabolic disorders. ${ }^{27-29}$ Many inflammatory cytokines, such as TNF- $\alpha$ and IL-1 $\beta$, were potentially involved in joint destruction, ${ }^{30}$ the prominent symptom of RA. Recently, it has been reported that azilsartan reduced TNF- $\alpha$ and IL- $1 \beta$ levels in an animal model of oral mucositis; ${ }^{31}$ although this finding is not directly correlated with the pathogenesis of arthritis, the outcome of this animal study encouraged our efforts toward performing the present clinical study. Based on the reported improvement in the clinical scores, the use

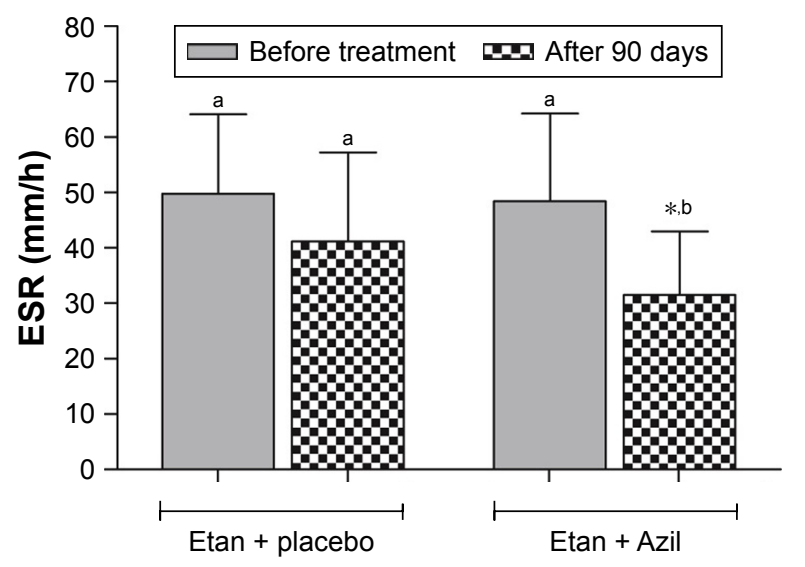

Figure 2 Effect of Azil on the ESR of patients with active RA maintained on Etan. Notes: *Significantly different from baseline in each group (paired $t$-test, $P<0.05$ ). Values with non-identical superscripts $(a, b)$ among groups were significantly different (ANOVA, $P<0.05$ ).

Abbreviations: ANOVA, analysis of variance; Azil, azilsartan; ESR, erythrocyte sedimentation rate; Etan, etanercept; RA, rheumatoid arthritis. of azilsartan may positively impact the process of tissue degeneration when administered for an extended period of time. This finding complies with many previously reported data, where blockade of RAS function decreases expression of many pro-inflammatory cytokines that may be attributed to different mechanisms, among them the suppression of reactive oxygen species (ROS) generation and downregulation of mediators involved in destructive inflammatory processes..$^{32,33}$ Meanwhile, many reports have demonstrated that immune cells, including macrophages and $\mathrm{T}$ cells, expressed RAS components that effectively participated in the local production of Ang II..$^{34,35}$ It has also been reported that AT1 receptors are expressed in the human synovium, ${ }^{34}$ in addition to the increased angiotensin-converting enzyme (ACE) activity in the synovial fluid of RA patients. ${ }^{36}$ In the present study, azilsartan enhanced the antiarthritic activity

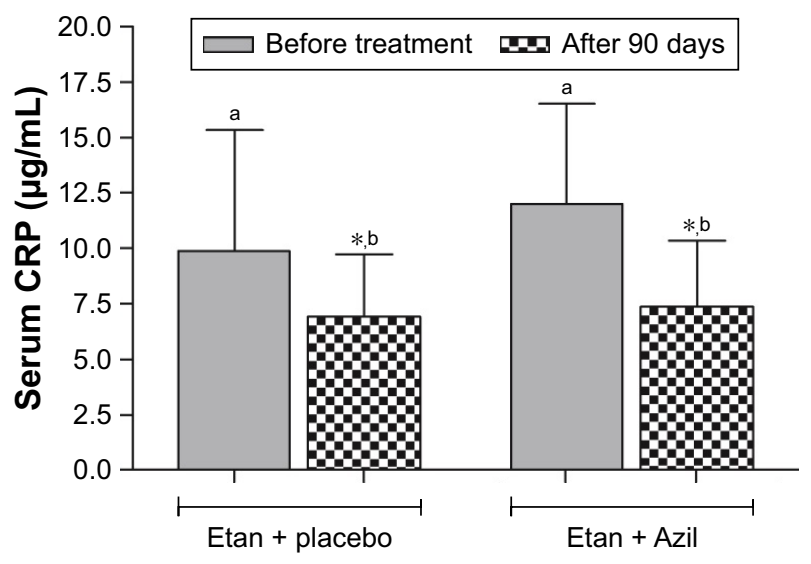

Figure 3 Effect of Azil on serum CRP of patients with active RA maintained on Etan. Notes: Values with non-identical superscripts $(a, b)$ among groups were significantly different (ANOVA, $P<0.05$ ). *Significantly different from baseline in each group (paired $t$-test, $P<0.05$ ).

Abbreviations: Azil, azilsartan; CRP, C-reactive protein level; Etan, etanercept; RA, rheumatoid arthritis. 
of etanercept, with significantly higher improvement in the clinical scores compared to using placebo formula with etanercept. More recently, we reported that coadministration of azilsartan may improve the effects of methotrexate on the clinical scores and certain inflammatory biomarkers of patients with active RA improperly managed with MTX alone. ${ }^{37}$ Although the effect of azilsartan alone was not evaluated due to ethical considerations, its concomitant use with other antiarthritic agents may show promising results, and future studies with larger patient samples and longer duration are needed to elucidate the effective role of RAS blockade in this regard. Azilsartan or other ARBs that have a pleiotropic function are well-known to hinder certain types of inflammatory processes through inhibiting neutrophil migration, attenuation of the exaggerated immune function or through the PPAR- $\gamma$ pathway. ${ }^{38}$ Moreover, azilsartan effectively attenuates tissue damage and granulation tissue formation in an experimental animal model of non-alcoholic fatty liver disease (NAFLD) ${ }^{28}$ and may be suggested as a part of a future therapeutic strategy of chronic inflammatory disorders. Rheumatoid arthritis was a disease of heterogeneous nature, and the use of single disease activity variable for diagnosis and treatment follow up was not considered as a valid or accurate approach. Therefore, we follow the ACR recommendation and utilize multiple variables (eg, DAS-28, HAQ-DI, CDAI or SDAI) for measurement of RA severity and treatment follow-up. ${ }^{39}$ The obtained results seem to be consistent in all types of the clinical scores followed during the study, which clearly showed significant reduction in disease activity. However, we cannot exclude the variation in the outcome of the different areas within each evaluation system followed during the study, which may be attributed to the sample size limitation of the study and other factors, including the personal variability in the response to treatment with a biologic agent like etanercept.

\section{Conclusion}

Blocking RAS with azilsartan may improve the effects of etanercept on certain clinical markers of disease severity of patients with active RA not responding to methotrexate.

\section{Acknowledgments}

The data were abstracted from a PhD thesis submitted by Naza MA Mahmood to the Department of Pharmacology, College of Medicine, University of Sulaimani. The project was approved and financially supported by the University of Sulaimani (Certificate ID: SA 507/1024). The authors gratefully thank the University of Sulaimani for support and the Center of Rheumatology in Sulaimani City for technical support.

\section{Author contributions}

All authors made substantial contributions to conception and design, acquisition of data, or analysis and interpretation of data; took part in drafting the article or revising it critically for important intellectual content; gave final approval of the version to be published; and agree to be accountable for all aspects of the work.

\section{Disclosure}

The author reports no conflicts of interest in this work.

\section{References}

1. Suzuki A, Yamamoto K. From genetics to functional insights into rheumatoid arthritis. Clin Exp Rheumatol. 2015;33(4 Suppl 92):S40-S43.

2. Picerno V, Ferro F, Adinolfi A, Valentini E, Tani C, Alunno A. One year in review: the pathogenesis of rheumatoid arthritis. Clin Exp Rheumatol. 2015;33(4):551-558.

3. Lampropoulos CE, Orfanos P, Bournia VK, et al. Adverse events and infections in patients with rheumatoid arthritis treated with conventional drugs or biologic agents: a real world study. Clin Exp Rheumatol. 2015; 33(2):216-224.

4. López-González R, León L, Loza E, Redondo M, Garcia de Yébenes MJ, Carmona L. Adherence to biologic therapies and associated factors in rheumatoid arthritis, spondyloarthritis and psoriatic arthritis: a systematic literature review. Clin Exp Rheumatol. 2015;33(4):559-569.

5. Phull AR, Nasir B, Haq IU, Kim SJ. Oxidative stress, consequences and ROS mediated cellular signaling in rheumatoid arthritis. Chem Biol Interact. 2018;281:121-136.

6. Hussain SA, Mortada AH, Jasim NA, Gorial FI. Silibinin improves the effects of methotrexate in patients with active rheumatoid arthritis: pilot clinical study. Oman Med J. 2016;31(4):263-269.

7. Nguyen G. Renin, (pro)renin and receptor: an update. Clin Sci (Lond). 2011;120(5):169-178.

8. Ruiz-Ortega M, Lorenzo O, Suzuki Y, Rupérez M, Egido J. Proinflammatory actions of angiotensins. Curr Opin Nephrol Hypertens. 2001; 10(3):321-329.

9. Peng J, Gurantz D, Tran V, Cowling RT, Greenberg BH. Tumor necrosis factor-alpha-induced AT1 receptor upregulation enhances angiotensin II-mediated cardiac fibroblast responses that favor fibrosis. Circ Res. 2002;91(12):1119-1126.

10. Wassmann S, Stumpf M, Strehlow K, et al. Interleukin-6 induces oxidative stress and endothelial dysfunction by overexpression of the angiotensin II type 1 receptor. Circ Res. 2004;94(4):534-541.

11. Wang D, Hu S, Zhu J, et al. Angiotensin II type 2 receptor correlates with therapeutic effects of losartan in rats with adjuvant-induced arthritis. J Cell Mol Med. 2013;17(12):1577-1587.

12. Refaat R, Salama M, Abdel Meguid E, El Sarha A, Gowayed M. Evaluation of the effect of losartan and methotrexate combined therapy in adjuvant-induced arthritis in rats. Eur J Pharmacol. 2013;698(1-3): 421-428.

13. Biliavska I, Stamm TA, Martinez-Avila J, et al. Application of the 2010 ACR/EULAR classification criteria in patients with very early inflammatory arthritis: analysis of sensitivity, specificity and predictive values in the SAVE study cohort. Ann Rheum Dis. 2013;72(8):1335-1341.

14. van Riel PL, Taggart AJ, Sany J, et al. Efficacy and safety of combination etanercept and methotrexate versus etanercept alone in patients with rheumatoid arthritis with an inadequate response to methotrexate: the ADORE study. Ann Rheum Dis. 2006;65(11):1478-1483.

15. Prevoo ML, van 't Hof MA, Kuper HH, van Leeuwen MA, van de Putte LB, van Riel PL. Modified disease activity scores that include twenty-eight-joint counts. Development and validation in a prospective longitudinal study of patients with rheumatoid arthritis. Arthritis Rheum. 1995;38(1):44-48. 
16. Smolen JS, Breedveld FC, Schiff MH, et al. A simplified disease activity index for rheumatoid arthritis for use in clinical practice. Rheumatology. 2003;42(2):244-257.

17. Ghosh A, Ghosh B, Pain S, et al. Comparison between DAS28, CDAI and HAQ-DI as tools to monitor early rheumatoid arthritis patients in eastern India. Indian Journal of Rheumatology. 2011;6(3):116-122.

18. Menk M, Graw JA, von Haefen C, et al. Stimulation of the Angiotensin II AT2 Receptor is Anti-inflammatory in Human LipopolysaccharideActivated Monocytic Cells. Inflammation. 2015;38(4):1690-1699.

19. Wang X, Khaidakov M, Ding Z, et al. Cross-talk between inflammation and angiotensin II: studies based on direct transfection of cardiomyocytes with AT1R and AT2R cDNA. Exp Biol Med. 2012;237(12): 1394-1401.

20. Paul M, Poyan Mehr A, Kreutz R. Physiology of local renin-angiotensin systems. Physiol Rev. 2006;86(3):747-803.

21. Weir MR. Effects of renin-angiotensin system inhibition on end-organ protection: can we do better? Clin Ther. 2007;29(9):1803-1824.

22. Nataraj C, Oliverio MI, Mannon RB, et al. Angiotensin II regulates cellular immune responses through a calcineurin-dependent pathway. J Clin Invest. 1999;104(12):1693-1701.

23. Kojima C, Kawakami A, Takei T, Nitta K, Yoshida M. Angiotensinconverting enzyme inhibitor attenuates monocyte adhesion to vascular endothelium through modulation of intracellular zinc. J Pharmacol Exp Ther. 2007;323(3):855-860.

24. Al-Hijjaj WK, Numan IT, Al-Sa'ad RZ, Hussain SA. Anti-inflammatory activity of telmisartan in rat models of experimentally-induced chronic inflammation: Comparative study with dexamethasone. Saudi Pharm J. 2011;19(1):29-34.

25. Tsuruoka S, Kai H, Usui J, et al. Effects of irbesartan on inflammatory cytokine concentrations in patients with chronic glomerulonephritis. Intern Med. 2013;52(3):303-308.

26. Pang T, Benicky J, Wang J, Orecna M, Sanchez-Lemus E, Saavedra JM. Telmisartan ameliorates lipopolysaccharide-induced innate immune response through peroxisome proliferator-activated receptor- $\gamma$ activation in human monocytes. J Hypertens. 2012;30(1):87-96.

27. Liu H, Mao P, Wang J, Wang T, Xie CH. Azilsartan, an angiotensin II type 1 receptor blocker, attenuates tert-butyl hydroperoxide-induced endothelial cell injury through inhibition of mitochondrial dysfunction and anti-inflammatory activity. Neurochem Int. 2016;94:48-56.
28. Hussain SA, Utba RM, Assumaidaee AM. Effects of Azilsartan, Aliskiren or their Combination on High Fat Diet-induced Non-alcoholic Liver Disease Model in Rats. Med Arch. 2017;71(4):251-255.

29. Silveira KD, Coelho FM, Vieira AT, et al. Mechanisms of the antiinflammatory actions of the angiotensin type 1 receptor antagonist losartan in experimental models of arthritis. Peptides. 2013;46:53-63.

30. Blüml S, Redlich K, Smolen JS. Mechanisms of tissue damage in arthritis. Semin Immunopathol. 2014;36(5):531-540.

31. de Araújo AA, Varela H, de Medeiros CA, et al. Azilsartan reduced TNF- $\alpha$ and IL-1 $\beta$ levels, increased IL-10 levels and upregulated VEGF, FGF, KGF, and TGF- $\alpha$ in an oral mucositis model. PLoS One. 2015; 10(2):e0116799.

32. Ruiz-Ortega M, Lorenzo O, Rupérez M, König S, Wittig B, Egido J. Angiotensin II activates nuclear transcription factor kappaB through AT(1) and AT(2) in vascular smooth muscle cells: molecular mechanisms. Circ Res. 2000;86(12):1266-1272.

33. Suzuki Y, Ruiz-Ortega M, Lorenzo O, Ruperez M, Esteban V, Egido J. Inflammation and angiotensin II. Int J Biochem Cell Biol. 2003;35(6): 881-900.

34. Walsh DA, Suzuki T, Knock GA, Blake DR, Polak JM, Wharton J. AT1 receptor characteristics of angiotensin analogue binding in human synovium. Br J Pharmacol. 1994;112(2):435-442.

35. Walsh DA, Catravas J, Wharton J. Angiotensin converting enzyme in human synovium: increased stromal $\left[{ }^{(125)} \mathrm{I}\right] 351 \mathrm{~A}$ binding in rheumatoid arthritis. Ann Rheum Dis. 2000;59(2):125-131.

36. Veale D, Yanni G, Bresnihan B, Fitzgerald O. Production of angiotensin converting enzyme by rheumatoid synovial membrane. Ann Rheum Dis. 1992;51(4):476-480.

37. Mahmood NMA, Hussain SA, Khan HAEK. Azilsartan as "Add-On" Treatment with Methotrexate Improves the Disease Activity of Rheumatoid Arthritis. Biomed Res Int. 2018;2018:7164291.

38. Matsushita K, Yang HC, Mysore MM, et al. Effects of combination PPAR $\gamma$ agonist and angiotensin receptor blocker on glomerulosclerosis. Lab Invest. 2016;96(6):602-609.

39. Anderson J, Caplan L, Yazdany J, et al. Rheumatoid arthritis disease activity measures: American College of Rheumatology recommendations for use in clinical practice. Arthritis Care Res. 2012;64(5): 640-647.
Therapeutics and Clinical Risk Management

\section{Publish your work in this journal}

Therapeutics and Clinical Risk Management is an international, peerreviewed journal of clinical therapeutics and risk management, focusing on concise rapid reporting of clinical studies in all therapeutic areas, outcomes, safety, and programs for the effective, safe, and sustained use of medicines. This journal is indexed on PubMed Central, CAS,

\section{Dovepress}

EMBase, Scopus and the Elsevier Bibliographic databases. The manuscript management system is completely online and includes a very quick and fair peer-review system, which is all easy to use. Visit http://www.dovepress.com/testimonials.php to read real quotes from published authors. 